\title{
MONITORING DISASTER-RELATED POWER OUTAGES USING NASA BLACK MARBLE NIGHTTIME LIGHT PRODUCT
}

\author{
Z. Wang ${ }^{1,2}$, M. O. Román ${ }^{1}$, Q. Sun ${ }^{1,3}$, A. L. Molthan ${ }^{4}$, L. A. Schultz ${ }^{4}$, V. L. Kalb ${ }^{1}$ \\ ${ }^{1}$ Terrestrial Information Systems Laboratory, NASA Goddard Space Flight Center, USA - zhuosen.wang@ nasa.gov; \\ miguel.o.roman@nasa.gov; virginia.1.kalb@nasa.gov \\ ${ }^{2}$ Earth System Science Interdisciplinary Center, University of Maryland, College Park, MD, USA \\ ${ }^{3}$ Science Systems and Applications, Inc., Lanham, MD, USA - qingsong.sun@ nasa.gov \\ 4Earth Science Office, NASA Marshall Space Flight Center, Huntsville, AL, USA - andrew.molthan@nasa.gov; \\ lori.a.schultz@nasa.gov
}

Commission III, ICWG III/Iva

KEY WORDS: Nighttime Lights, VIIRS, Disaster Response, Power Outages, NASA's Black Marble, Albedo, Lunar BRDF

\begin{abstract}
:
Timely and accurate monitoring of disruptions to the electricity grid, including the magnitude, spatial extent, timing, and duration of net power losses, is needed to improve situational awareness of disaster response and long-term recovery efforts. Satellite-derived Nighttime Lights (NTL) provide an indication of human activity patterns and have been successfully used to monitor disaster-related power outages. The global $500 \mathrm{~m}$ spatial resolution National Aeronautics and Space Administration (NASA) Black Marble NTL daily standard product suite (VNP46) is generated from Visible Infrared Imaging Radiometer Suite (VIIRS) Day/Night Band (DNB) onboard the NASA/National Oceanic and Atmospheric Administration (NOAA) Suomi National Polar-orbiting Partnership (SuomiNPP) satellite, which began operations on 19, January 2012. With its improvements in product accuracy (including critical atmospheric and BRDF correction routines), the VIIRS daily Black Mable product enables systematic monitoring of outage conditions across all stages of the disaster management cycle.
\end{abstract}

\section{INTRODUCTION}

The loss of electrical power after major disasters (e.g. hurricane, winter storms, floods, and earthquakes) significantly affects the lives of citizens, with ripple effects that may last for several days or months. The United Nations 2030 Agenda for Sustainable Development and the Sendai Framework for Disaster Risk Reduction aims to promote more resilient infrastructure, and therefore reduce the impacts of disasters and strengthen the sustainability of cities (Aitsi-Selmi et al., 2016; Lubchenco et al., 2015; Roberts et al., 2015). The quantitative estimation of resilience metrics related to energy infrastructure (e.g., failure/recovery) are useful for post-disaster activities. This is especially true since the failure of ground-based information systems can often hamper disaster response and relief efforts. The remote-sensed satellite data can provide an independent and complementary source of information to monitor impacts to key lifelines of the electricity infrastructure.

The space-borne Nighttime Light (NTL) satellite data was first provided by the Defense Meteorological Satellite Program's Operational Line Scanner (DMSP/OLS) (Elvidge et al., 1997). However, the lack of onboard DMSP/OLS calibration and saturation in bright urban areas prevent the quantitative radiance variation analysis to monitor outage conditions. The Day/Night Band (DNB) sensor of the Visible Infrared Imaging Radiometer Suite (VIIRS) on board the Suomi-National Polarorbiting Partnership (Suomi NPP) has significantly improved calibration performance (Lee et al., 2015; Liao et al., 2013; Xiong et al., 2014), therefore increasing the accuracy of NTL products (Román et al., 2018). The satellite NTL products have been widely used for urban remote sensing science and applications across spatial and temporal scales (Chen and Nordhaus, 2015; Guo et al., 2015; Levin and Zhang, 2017; Li et al., 2013; Ma et al., 2014; Sharma et al., 2016; Yu et al., 2015).

A primary source of input in any quantitative NTL product is the specification of Lunar irradiance. This is particularly true for daily NTL products since: (1) moonlight is a dominant source of noise that impacts the analysis of surface artificial lights; (2) the amount of reflected lunar radiance is comparative to the lit environment of villages or small towns, in particular over surfaces with high albedos (Román et al., 2018); (3) the contribution from Lunar radiance impacts analyses of temporal NTL patterns (e.g. power outage monitoring).

\section{DATA}

\subsection{Study Area}

In this study, the NASA daily Black Marble NTL product was used to monitor the variations in the spatial extent, timing and recovery of energy services during the aftermath of Hurricane Sandy in 2012 and María in 2017 by conducting spatial and temporal analyses across different levels of urbanization.

Hurricane Sandy, a Category 2 storm at its peak intensity, made a historic landfall on the northeastern coast of U.S.A. with the hardest-hit over New York City and northeastern New Jersey (Figure 1). It caused flooding streets and left more than eight million people without electricity during late October 2012 (Cao et al., 2013; Cole et al., 2017). The power grid was suspended for several days at some areas. The Hurricane María devastated Puerto Rico in September, 2017 and led to the 
longest and largest major power outage in modern U.S. history which created a humanitarian crisis. The massive damage to the island's aging network of transmission and distribution lines resulted in widespread outages. The power recovery is very slow and, as of January 2018, about half of Puerto Ricans are still without power.

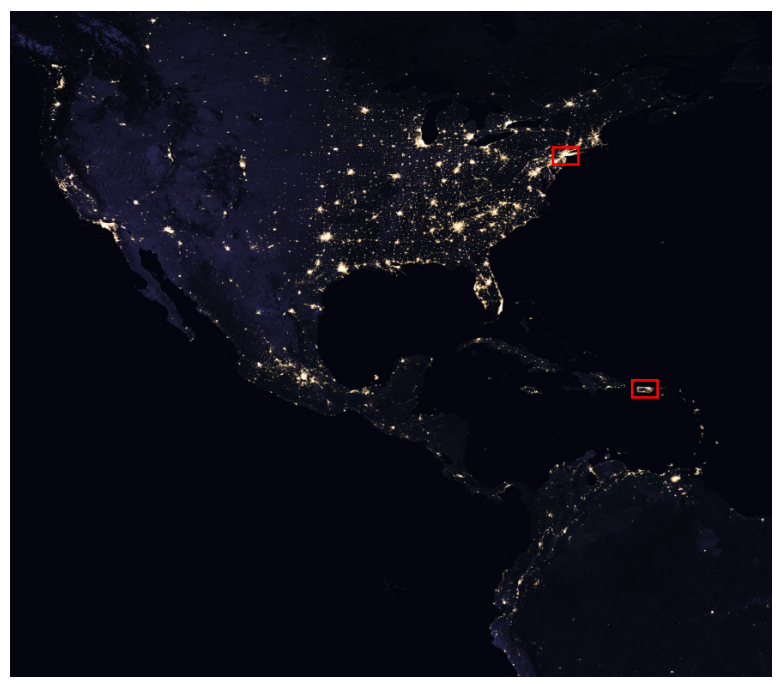

Figure 1. The NASA Black Marble annual composite NTL in 2016. The two red rectangular boxes represent the study areas of Puerto Rico and New York City and northeastern New Jersey.

\subsection{NASA Black Marble Product}

The Black Marble product retrieval strategy uses a novel "Turning off the Moon" approach that combines cloud-free, atmospheric-, terrain-, vegetation-, snow-, lunar-, and stray light-corrected nighttime VIIRS DNB radiances, daytime DNB surface reflectance, Bidirectional Reflectance Distribution Function (BRDF)/Albedo, and Lunar irradiance values to minimize the influence of extraneous artifacts and biases (Román et al., 2018; Román and Stokes, 2015). The atmospheric correction routines used in Black Marble NTL processing rely on the use of accurate vector radiative transfer modelling of the coupled atmosphere-surface system to compensate for aerosols, water vapor, and ozone impacts on the NTL radiances. The lunar contribution on the DNB radiance is estimated and removed by integrating a post-launch lunar irradiance model of the VIIRS DNB with surface BRDF/albedo retrievals. The removal of lunar cycle radiance enables first-ever generation of temporally-consistent daily products. Canopy radiative transfer modelling is also used to account for the seasonal variations due to vegetation phenology in NTL.

After properly accounting for these systematic sources of uncertainty and measurement error, the VIIRS DNB's ultrasensitivity and daily frequency enables global mapping of abrupt short-term changes such as conflict-associated demographic shifts and disaster-driven power losses, seasonal changes driven by reoccurring human activities (e.g., the Holidays), as well as gradual changes due to electrification (e.g. rural development) and economic conditions (e.g. coal mine abandonment). The preliminary evaluation activity from a stable point light source deployed in Puerto Rico indicates that the NASA Black Marble NTL product can successfully detect a daily change of $0.43 \mathrm{nW} \cdot \mathrm{cm}^{-2} \cdot \mathrm{sr}^{-1}$. This unprecedent degree of precision beats the current JPSS requirement by a factor of $7 \mathrm{x}$. The BRDF and albedo, retrieved from daytime multi-angular DNB surface reflectance observations, was shown to be essential for the removal of extraneous sources of NTL emissions in the Black Marble VNP46 product (Román et al., 2018). The Black Marble NTL products, produced at NASA's Land Science Investigator-led Processing Systems (Land SIPS), is available at $500 \mathrm{~m}$ resolution since 19 January, 2012.

\section{METHODOLOGY}

\subsection{Power Outage Extent}

The overall extent of outage affected communities was detected through comparison of pre-hurricane and post-hurricane NTL data. Since the accuracy of cloud mask has been shown to affect the power outage estimation, short multi-days aggregation methods are applied to reduce the spatial extent estimation error.

The pixel-based percent of normal NTL was used to detect the spatial extend of power outage (Cao et al. 2013, Cole et al., 2017):

$$
\text { Percent }_{\text {normal }}=\frac{N T L_{\text {post-event }}}{N T L_{\text {before-event }}}
$$

Where NTL post-event is the NTL after the disaster. The NTL beforeevent is the NTL before the disaster. Here, the gap-filled VNP46 NTL values on October 26, 2012 and September 17, 2017 are used to serve as before-event NTL for Hurricane Sandy and Hurricane Maria respectively.

\subsection{Power Outage Recovery Metrics}

The power recovery metrics, including recovery start date, recovery duration and recovery rate were estimated from the daily temporal Black Marble NTL trajectory with the prehurricane NTL serving as baseline data.

\begin{tabular}{|l|l|}
\hline Name & Definition \\
\hline Recovery start date & $\begin{array}{l}\text { The date when the power } \\
\text { starts to recover }\end{array}$ \\
\hline Recovery duration & $\begin{array}{l}\text { The number of days between } \\
\text { the recovery start date and } \\
\text { the date when the power is } \\
\text { fully recovered }\end{array}$ \\
\hline Recovery rate & $\begin{array}{l}\text { The linear slope of NTL } \\
\text { change during the recovery } \\
\text { period }\end{array}$ \\
\hline
\end{tabular}

Table 1. Power outage recovery metrics

We note that this quantitively analysis is only possible when using atmospheric- and lunar irradiance- corrected NTL datasets. The lunar cycle contamination could result in false power recovery estimation. The power recovery could also be missed if moon-less only data were used since most of the power outrage recoveries take place during a short time period. 


\section{RESULTS}

\subsection{Power Outage Extent}

The power outage lasted around one week over the New York City and northeast New Jersey area. November 1 is the first relatively clear day after the hurricane. However, that day is nearly full moon, the lunar radiances have to be removed to quantify the power outage extent. With the lunar corrected Black Marble product, the power outage spatial extent indicates that the middle areas of the Long Island and the northeast of New Jersey, in particular the coastal areas (e.g. Middletown, Atlantic city) experienced the largest percent of power outage (Figure 2).
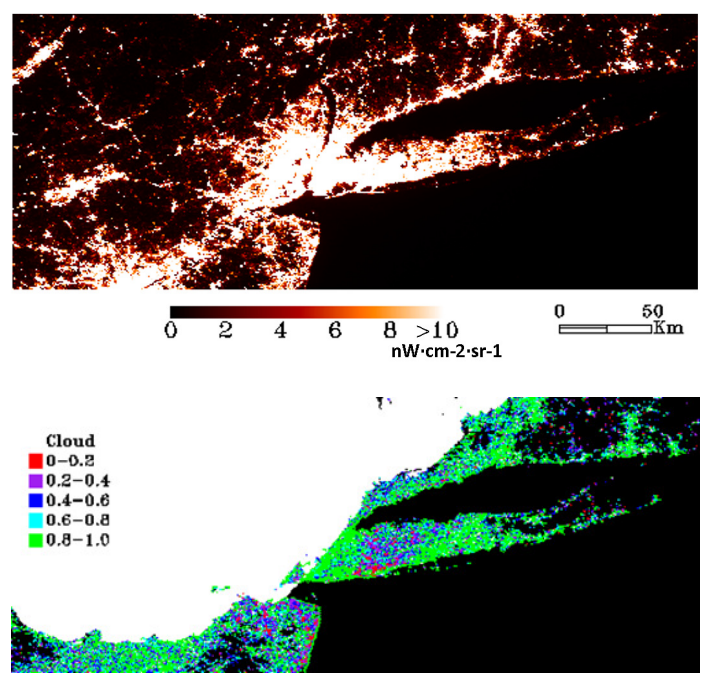

Figure 2. (A) The NASA Black Marble NTL before the Hurricane Sandy; (B) The percent of normal NTL power outage spatial extent. The NTL on November 1 is used for posthurricane. The white colour areas were covered by cloud.

Puerto Rico experienced significant power outage after the Hurricane Maria (Figure 3). The percent of normal is less than $40 \%$ over most area of the Puerto Rico.

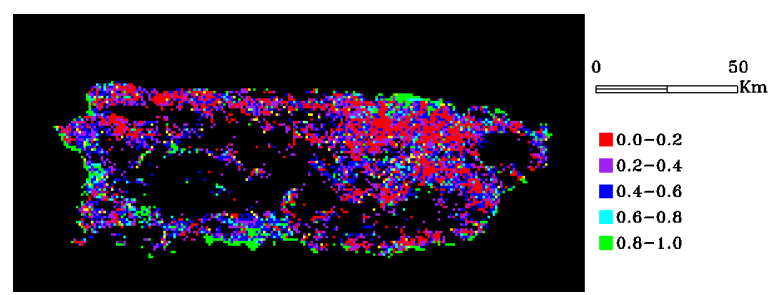

Figure 3. The percent of normal NTL power outage spatial extent. The NTL on September 30 is used for post-hurricane.

\subsection{Post-hurricane Recovery}

Figure 4 shows the post-hurricane power recovery at Aguadilla, Puerto Rico. Aguadilla totally lost power immediately after the hurricane. The power started to slowly recover after one month and became fully recovered after four months. The recovery rate is $0.02 \mathrm{nW} \cdot \mathrm{cm}^{-2} \cdot \mathrm{sr}^{-1}$ per day. The power of lots of areas in Puerto Rico are still not fully recovered even today which is six months after the hurricane.

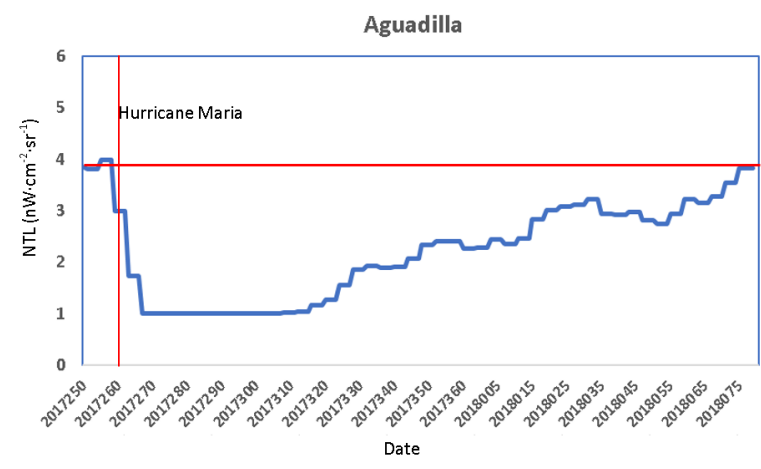

Figure 4. The post-hurricane NTL recovery at Aguadilla, Puerto Rico.

The power outrage spatial extent and power recovery after hurricane estimated from NASA Black Marble NTL product match well with official reports (DOE, 2017).

\section{CONCLUSIONS}

This study indicates that the Black Marble NTL product can monitor the power outages spatial extent and recovery status at community levels and serves as good data source to locate the areas that require disaster relief. The information derived from NASA's Black Marble products is being used, for example, to better position specialized equipment near affected areas (e.g., diesel generators in remote parts of Puerto Rico and the lower Antilles) while also helping familiarize residents of their current situation. These efforts, while still in their research phase, have the potential to improve the overall timing, decision making, and effectiveness of search and rescue efforts for future disasters.

\section{REFERENCES}

Aitsi-Selmi, A., Blanchard, K., and Murray, V., 2016. Ensuring science is useful, usable and used in global disaster risk reduction and sustainable development: a view through the Sendai framework lens. Palgrave Communications, 2, 16016. doi:10.1057/palcomms.2016.16

Cao, C., Shao, X., and Uprety, S., 2013. Detecting light outages after severe storms using the S-NPP/VIIRS day/night band radiances. IEEE Geoscience and Remote Sensing Letters, 10, pp.1582-1586.

Chen, X. and Nordhaus, W., 2015. A test of the new VIIRS lights data set: Population and economic output in Africa. Remote Sensing, 7, pp.4937-4947.

Cole, T.A., Wanik, D.W., Molthan, A.L., Román, M.O., and Griffin, R.E., 2017. Synergistic Use of Nighttime Satellite Data, Electric Utility Infrastructure, and Ambient Population to Improve Power Outage Detections in Urban Areas. Remote Sensing, 9(3), 286. doi:10.3390/rs9030286

DOE. 2017. Hurricanes Nate, Maria, Irma, and Harvey Situation Reports. Department of Energy Available at: https://energy.gov/oe/downloads/hurricanes-nate-maria-irmaand-harvey-situation-reports.

Elvidge, C.D., Baugh, K.E., Kihn, E.A., Kroehl, H.W., Davis, E.R., and Davis, C.W., 1997. Relation between satellite 
observed visible-near infrared emissions, population, economic activity and electric power consumption. International Journal of Remote Sensing, 18, pp. 1373-1379.

Guo, W., Lu, D., Wu, Y., and Zhang, J., 2015. Mapping impervious surface distribution with integration of SNNP VIIRS-DNB and MODIS NDVI data. Remote Sensing, 7, pp. $12459-12477$.

Lee, S., McIntire, J., Oudrari, H., Schwarting, T., and Xiong, X., 2015. A new method for Suomi-NPP VIIRS day-night band on-orbit radiometric calibration. IEEE Transactions on Geoscience and Remote Sensing, 53, pp. 324-334.

Levin, N. and Zhang, Q., 2017. A global analysis of factors controlling VIIRS nighttime light levels from densely populated areas. Remote Sensing of Environment, 190, pp. 366-382.

Li, X., Xu, H., Chen, X., and Li, C., 2013. Potential of NPPVIIRS nighttime light imagery for modeling the regional economy of China. Remote Sensing, 5, pp. 3057-3081.

Liao, L.B., Weiss, S., Mills, S., and Hauss, B., 2013. Suomi NPP VIIRS day-night band on-orbit performance. Journal of Geophysical Research Atmospheres, 118, pp. 12705-12718.

Lubchenco, J., Barner, A.K., Cerny-Chipman, E.B., and Reimer, J.N., 2015. Sustainability rooted in science. Nature Geoscience, 8, pp. 741-745.

Ma, B.D., Wu, L.X., Zhang, X.X., Li, X.C., Liu, Y., and Wang, S.L., 2014. Locally adaptive unmixing method for lake-water area extraction based on MODIS $250 \mathrm{~m}$ bands. International Journal of Applied Earth Observation and Geoinformation, 33, pp. 109-118.

Roberts, E., Andrei, S., Huq, S., and Flint, L., 2015. Resilience synergies in the post-2015 development agenda. Nature Climate Change, 5, pp. 1024-1025.

Román, M.O. and Stokes, E.C., 2015. Holidays in lights: Tracking cultural patterns in demand for energy services. Earth's Future, 3, pp. 182-205.

Román, M.O., Wang, Z., Sun, Q., Kalb, V., Miller, S., Molthan, A., Schultz, L., Bell, J., Stokes, E., Pandey, B., Seto, K., Hall, D., Oda, T., Wolfe, R., Lin, G., Golpayegani, N., Devadiga, S., Davidson, C., Sarkar, S., Praderas, C., Schmaltz, J., Boller, R., Stevens, J., González, O.M.R., Padilla, E., Alonso, J., Detrés, Y., Armstrong, R., Miranda, I., Conte, Y., Marrero, N., MacManus, K., Esch, T., and Masuoka, E.J., 2018. NASA's Black Marble nighttime lights product suite. Remote Sensing of Environment, 210, pp. 113-143.

Sharma, R.C., Tateishi, R., Hara, K., Gharechelou, S., and Iizuka, K., 2016. Global mapping of urban built-up areas of year 2014 by combining MODIS multispectral data with VIIRS nighttime light data. International Journal of Digital Earth,9, pp. 1004-1020.

Xiong, X., Butler, J., Chiang, K., Efremova, B., Fulbright, J., Lei, N., McIntire, J., and Wang, Z., 2014. VIIRS on-orbit calibration and performance update. International Geoscience and Remote Sensing Symposium (IGARSS), pp. 1389-1392.

Yu, B., Shi, K., Hu, Y., Huang, C., Chen, Z., and Wu, J., 2015.
Poverty evaluation using NPP-VIIRS nighttime light composite data at the county level in China. IEEE Journal of Selected Topics in Applied Earth Observations and Remote Sensing, 8, pp. 1217-1229. 